\title{
STUDY ON ADHERENCE TO CAPECITABINE AMONG PATIENTS WITH COLORECTAL CANCER AND METASTATIC BREAST CANCER
}

\author{
Adiel Goes de FIGUEIREDO JUNIOR and Nora Manoukian FORONES
}

\begin{abstract}
Context - Capecitabine, an oral drug, is as effective as traditional chemotherapy drugs. Objectives - To investigate the adhesion to treatment with oral capecitabine in breast and colorectal cancer, and to determine any correlation with changes in patient's quality of life. Methods - Patients with colorectal cancer or breast cancer using capecitabine were included. The patients were asked to bring any medication left at the time of scheduled visits. The QLQ-C30 questionnaire was applied at the first visit and 8-12 weeks after treatment. Results - Thirty patients were evaluated. Adherence was $88.3 \%$ for metastatic colon cancer, $90.4 \%$ for non-metastatic colon cancer, $94.3 \%$ for rectal cancer and $96.2 \%$ for metastatic breast cancer. No strong correlation between adherence and European Organisation for Research and Treatment of Cancer QLQ-C30 functional or symptom scale rates had been found. There was no statistically significant correlation between compliance and the functional and symptom scales of the questionnaire before and after chemotherapy, with the exception of dyspnea. Conclusion - Although no absolute adherence to oral capecitabine treatment had been observed, the level of adherence was good. Health professionals therefore need a greater focus in the monitoring the involvement of patients with oral treatment regimens. Patients with lesser degrees of dyspnea had greater compliance.
\end{abstract}

HEADINGS - Colorectal neoplasms, therapy. Breast neoplasms, therapy. Medication adherence. Questionnaires.

\section{INTRODUCTION}

The traditional approach of chemotherapy against cancer targets the several phases of the cell cycle, thereby interfering in cell growth and division and leading to cell death. Many of these treatments act directly or indirectly on the synthesis and replication of DNA, for example: by means of interpolation of DNA, through blockage of components such as purine or antagonistic antifolates, through inhibition of the enzyme topoisomerase (which is necessary for DNA repair), or by inhibiting formation of the microtubules needed for mitosis. The adverse effects of these treatments are caused by the nonspecificity of these actions on malignant cells ${ }^{(1,12)}$.

Oral medication, in contrast with intravenous medications, has different side effect profiles and is better tolerated under some circumstances. Moreover, treatment options with greater flexibility for patients are likely to be used with higher frequency ${ }^{(5)}$. Studies have shown that patients prefer oral to intravenous chemotherapy, as long as the efficacy is not compromised $^{(4,17,18)}$. However, low adherence can become the greatest obstacle to an effective result from new oral agents, particularly if the oncologist fails to be aware of this potential problem.

The concepts of adherence vary greatly, but it can be defined as "the use of prescribed medications or other procedures at a minimum of $80 \%$ of their full amount, with due regard for times, doses and length of treatment ${ }^{(7)}$.

Adherence occurs when the patient's conduct towards taking the medication, following the diet and implementing changes in life style coincides with the clinical prescription ${ }^{(11)}$.

There are several methods for measuring adherence to a treatment, but none is substantially free of limitations. If the patient is aware that adherence is being evaluated, this can influence the result from the self-reporting method, in which the patient is invited to report how faithfully the prescribed regime was followed ${ }^{(2,5)}$.

Another method is to count the pills. In this, the physician asked the patient to return the remaining pills at each visit, so that the number of doses missed is calculated. This method can also overestimate the 
number of pills that were really taken, since the patients may disregard the doses that were not taken, in order to avoid being considered non-adherent. This method is an alternative or supplement to self-reporting. However, it does not supply information regarding the day and time at which the medication was taken, which may be a critical factor regarding the efficacy of treatment in some situations ${ }^{(24,26)}$.

Metabolic levels in serum or urine are measurements of adherence presenting greater objectivity, but also do not describe the day and time at which the medication was taken and can also be manipulated by patients (an extra dose of a medication may be taken before a visit). Furthermore, because of the variability in the pharmacokinetics of the drug (absorption, distribution, metabolism and excretion), the intervals that are coherent with adherence may be wider. To measure metabolic levels, small quantities of metabolites of the drug need to be detected in the patient's serum or urine, which is not always easily achieved ${ }^{(26)}$.

A microelectronic monitoring system (MEMS) can also measure adherence. These systems consist of a "smart" receptacle that registers each time that the top of the medicine container is removed. The MEMS provides a computerized report for each opening of the flask. Although it is considered to be less subject to manipulation, the pill that is taken out of the container may not be ingested ${ }^{(26)}$.

Low adherence to oral therapies may have multiple consequences and influence the efficacy of the treatment. If the doctor is not aware that the patient is not following the therapy as prescribed, the progression of the disease may attributed to lack of activity by the drug and, consequently, the doctor may unnecessarily change the prescribed regime. Among many patients, non-adherence has been associated with increased consumption of medical care and resources, including medical consultations and greater rates of hospitalization ${ }^{(28)}$.

Toxicity may increase if the patient is taking doses at intervals that are too close to each other, or at the wrong time of the day. When patients who take part in clinical trials are not adherent, this can result in imprecise information and erroneous dosage recommendations ${ }^{(5,26)}$. With the aim of limiting this type of error, most clinical trials include an adherence evaluation. However, adherence in a clinical trial tends to be much higher that normally observed, because self-reporting, with its biases, is the commonest method for evaluating adherence in these studies. In addition, the rates of adherence with oral medication in clinical trials are commonly greater, because of the careful selection of patients and the great attention given by the team to those who have been recruited ${ }^{(22,23)}$.

The effects of non-adherence are smaller in relation to drugs with a long half-life, in comparison with drugs with a short half-life, for which the consequence of wrong dosages can be higher ${ }^{(21,27)}$.

Capecitabine is an oral fluoropyrimidine that was developed in response to the clinical need for new treatment options, offering equal efficacy, better tolerability and convenience for patients ${ }^{(8,13)}$. Oral administration of this drug mimics the application of 5-FU in continuous infusion and saves the patient from the need for venous access to be implemented. The concentration of capecitabina in the tumor is almost 30 times higher than the plasma. The serum mean life of this drug is $30-45$ minutes.

The efficacy and safety of capecitabine has been documented in treatments for various tumor sites, as an adjuvant or palliative approach, in monotherapy or in association with other drugs, and as a radiosensitizer.

The objective of this study was to evaluate the adherence of metastatic breast cancer and colorectal cancer patients to treatment with capecitabine, by means of patient reporting and pill counts, in three consecutive evaluations.

\section{METHODS}

A prospective cohort study was carried out over an eighteen-month period (August 2009 to April 2011) including patients with colorectal cancer, with or without metastasis, and patients with metastatic breast cancer, who were using capecitabine in monotherapy or in association with other drugs, such as oxaliplatin or irinotecan, and drugs with molecular targets, such as bevacizumab. All the patients were treated at the adult chemotherapy outpatient service of Hospital São Paulo, Federal University of São Paulo.

The local ethics committee approved the study and all the patients signed a consent statement before taking part in the study.

Patients of both genders were included, with ages between 18 and 85 years. Individuals who were incapable of comprehending or consenting to their participation in the study were excluded.

The patients involved in the study were asked to bring back the leftover medicine (which had been given out at the start of each new cycle), at their return visits, so that the pillss could be counted with the intention of evaluating the adherence to the oral treatment. As well as the counts, the reports from the patients regarding any possible loss of pills were also assessed. In the event that pills were lost, they were also counted.

All the individuals answered the quality-of-life questionnaire QLQ-C30 (European Organisation for Research and Treatment of Cancer-EORTC) at the initial visit and 8 or 12 weeks after the beginning of the treatment ${ }^{(9)}$. The quality of life questionnaire had been correlated to adhesion.

\section{Statistical analysis}

The Wilcoxon test was used to compare the same variable at different times for each patient. Non-parametric statistical techniques has been done because the conditions for the use of parametric tests and techniques, such as normality and homogeneity of variance were not found. The Mann-Whitney test and the Kruskal-Wallis test were used to compare two or more variables simultaneously. Spearman's correlation was used to "measure" the interconnection among the variables. For the statistical analysis, the SPSS V16, Minitab 15 and Excel Office 2007 software were used. 


\section{RESULTS}

Thirty patients were studied, of which $20(66.6 \%)$ were female. The patients' mean age was 60.2 years $(\mathrm{SD}=14.06)$, and $63.3 \%$ were over the age of 60 years (Table 1 ).

Regarding the tumor location among the study participants, six $(20 \%)$ patients had metastatic breast cancer, nine $(30 \%)$ metastatic colon cancer, ten $(33.3 \%)$ rectal cancer and five $(16.7 \%)$ non-metastatic colon cancer (Table 1).

TABLE 1. Characterization of the sample according to sex, tumor site and treatment.

\begin{tabular}{llc}
\hline & & $\mathrm{n}(\%)$ \\
\hline \multirow{2}{*}{ Gender } & Female & $20(66.6 \%)$ \\
& Male & $10(33.4 \%)$ \\
\hline \multirow{2}{*}{$\begin{array}{l}\text { Site and } \\
\text { stage of } \\
\text { cancer }\end{array}$} & Metastatic breast & $06(20 \%)$ \\
& Metastatic colon & $09(30 \%)$ \\
& Nectal & $10(33.3 \%)$ \\
\multirow{2}{*}{ Treatment } & Capecitabine monotherapy & $05(16.7 \%)$ \\
& Capecitabine + Chemotherapy EV & $03(10 \%)$ \\
& Capecitabine + radiotherapy & $09(30 \%)$ \\
\hline
\end{tabular}

The adjuvant treatment for colon cancer had been done with oral capecitabina for eight cycles and for metastatic patient until progression disease.

Three $(10 \%)$ patients were treated with capecitabine in monotherapy, $18(60 \%)$ with capecitabine in association with other intravenous chemotherapeutic drugs and nine (30\%) received capecitabine together with radiotherapy.

The observed adherence values were $88.3 \%$ for metastatic colon cancer, $90.4 \%$ for non-metastatic colon cancer, $94.3 \%$ for rectal cancer and $96.2 \%$ for metastatic breast cancer. Although patients with non-metastatic disease presented a higher percentage adherence, this difference was not statistically significant. No difference between the tumor site and adherence was found, although breast cancer patients presented greater percentage adherence (Figure 1). Furthermore, although patients using capecit-

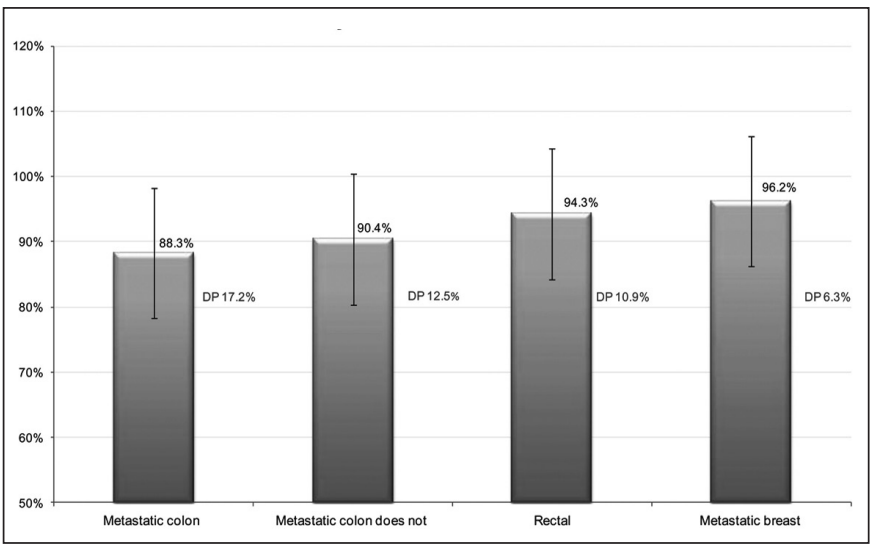

FIGURE 1. Adhrenece in relation to localization and stage of cancer abine in monotherapy had greater adherence than shown by those who used the medication in association with other chemotherapeutic drugs, these differences were not significant (Figure 2). Although patients did not are at the same cycle, the evaluation was done at the same time for all of them (between 8 to 12 weeks after the first treatment).

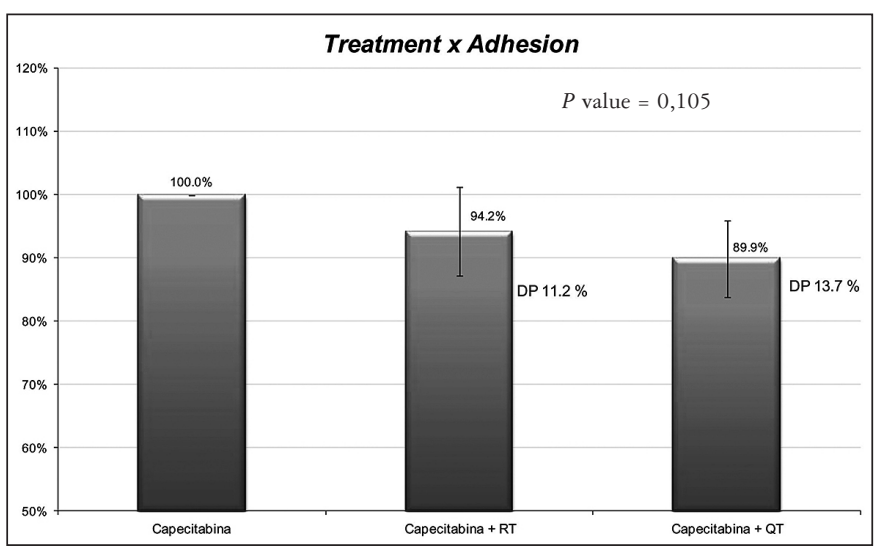

FIGURE 2. Adherence according to the chemotherapy used

The correlation analysis among the variables assessed using EORTC QLQ-C30 at the 1st and 2nd evaluations, regarding adherence to treatment with capecitabine, showed that there was a negative correlation between adherence and dyspnea (DYSP) before chemotherapy started.

The Wilcoxon test compared the results between qualityof-life evaluations before and after chemotherapy, for all the variables. These comparisons were made for each stage and each treatment, and for the whole sample (Table 2).

TABLE 2. Results between quality-of-life (EORTC QLC-30) evaluations before and after chemotherapy

\begin{tabular}{lccccc}
\hline & \multicolumn{2}{c}{ Adherence BCHT } & & \multicolumn{2}{c}{ Adherence ACHT } \\
& Corr & $\boldsymbol{P}$ & & Corr & $\boldsymbol{P}$ \\
\hline ESG & $-8.8 \%$ & 0.645 & ESG & $-2.3 \%$ & 0.904 \\
CFI & $12.4 \%$ & 0.513 & CFI & $-7.3 \%$ & 0.702 \\
CFU & $-1.6 \%$ & 0.932 & CFU & $-17.7 \%$ & 0.351 \\
CE & $3.3 \%$ & 0.862 & CE & $-6.4 \%$ & 0.739 \\
CC & $0.7 \%$ & 0.970 & CC & $-9.2 \%$ & 0.630 \\
CS & $26.5 \%$ & 0.158 & CS & $18.9 \%$ & 0.318 \\
FA & $-3.2 \%$ & 0.866 & FA & $2.2 \%$ & 0.910 \\
NA/VO & $3.2 \%$ & 0.866 & NA/VO & $-10.7 \%$ & 0.573 \\
DOR & $-9.5 \%$ & 0.619 & DOR & $-13.9 \%$ & 0.464 \\
DISP & $-37.4 \%$ & 0.042 & DISP & $-28.3 \%$ & 0.130 \\
INS & $-17.4 \%$ & 0.356 & INS & $-21.8 \%$ & 0.248 \\
PA & $-14.8 \%$ & 0.436 & PA & $-11.0 \%$ & 0.562 \\
CONST & $-3.7 \%$ & 0.847 & CONST & $-17.8 \%$ & 0.347 \\
DIA & $3.2 \%$ & 0.866 & DIA & $-13.6 \%$ & 0.472 \\
DF & $10.8 \%$ & 0.570 & DF & $5.7 \%$ & 0.764 \\
\hline
\end{tabular}

BCHT: before chemotherapy; ACHT: after chemotherapy; ESG: state of global health; CFI physical capacity; CFU: functional capacity; CE: emotional capacity; CC: cognitive capacity; CS: social capacity; FA: fatigue; NA/VO: nausea/vomiting; DOR: pain; DISP: dyspnea; INS insomnia; PA: loss of appetite; CONST: constipation; DIA: diarrhea; DF: financial difficulties. 


\section{DISCUSSION}

The focus of the present study was to evaluate the degree of adherence to the oral chemotherapy treatment with capecitabine among colorectal and metastatic breast cancer patients, and to identify, through the EORTC QLQ-C30 quality-of-life questionnaire, any characteristic among the group of patients studied that would make them more or less adherent to the treatment.

Among the patients studied, there was a greater proportion of female patients, since breast cancer patients were included. The mean age was 60.2 years, which is compatible with the literature for both types of neoplasia ${ }^{(14,31)}$.

To study adherence to oral chemotherapy, two of the most commonly used methods were chosen: structured interviews and counting of the units of medication that the patient still had at each consultation, before beginning a new cycle, because these methods are easily applied and have a lower cost. The greatest problem of these methods is overestimation of adherence, since, as mentioned earlier, patients may conceal from the interviewer that they have disregarded some pills.

Breast cancer patients had a greatest percentage adherence, which may show that the women had greater concern regarding the evolution of the disease. Non-metastatic disease patients had also higher percentages, possibly related to higher percentages of patients using capecitabine in monotherapy and patients with better performance status.

All the patients presented high adherence, above $80 \%{ }^{(3)}$. One of the most accepted definitions for good adherence states that this occurs when the use of the prescribed medications or other procedures occurs at a minimum of $80 \%$ of their full amount ${ }^{(7)}$.

This accepted proportion is arbitrary and not based on any objective data relating to response dose. To define adequate adherence, it would be important to develop studies on the efficacy of the dose. This would make it possible to evaluate adherence results in relation to clinical evolution. The importance of demonstrating the positive influence of clinically relevant results was discussed by Kripalani et al., who found that few adherence studies fulfilled this need ${ }^{(15)}$. Although the present study showed that the mean adherence was greater than $80 \%$, one limiting factor was the small number of participants.

In comparing the present study with others conducted previously, most of them concentrated on adherence to treatment relating to chronic diseases and sought to develop strategies for improving the adherence. There are also a great number of studies on adherence to medications among the elderly or individuals with mental disorders ${ }^{(6)}$. However, few studies on adherence to oral chemotherapy among cancer patients are available, as noted in a recent review ${ }^{(26)}$.

For cancer patients, a large proportion of the studies relate to use of tamoxifen. Using self-report methods, pill counting and microelectronic monitoring (MEMS), Waterhouse et al. evaluated the adherence of 24 breast cancer patients to oral therapy with tamoxifen. The adherence rates differed depending on the measurement strategy: self-reporting resulted in overall adherence of $98.6 \pm 2.2 \%$, pill counts presented $92.1 \pm$ $9.8 \%$ and microelectronic monitoring showed the lowest rate, with $85.4 \pm 17.2 \%\left({ }^{(29)}\right.$. Recently published results on adherence to the use of tamoxifen among 462 breast cancer patients over 5 years showed that $31 \%$ of the patients who started to use tamoxifen were unable to make use of the medication until the end of the recommended period ${ }^{(16)}$.

Others studies on adherence to capecitabine were published, and the data were similar to what was observed in the present study, especially in relation to breast cancer. Only $76 \%$ of the elderly patients with breast cancer received $80 \%$ or more of the prescribed doses ${ }^{(19)}$. On the other hand, in a younger breast cancer population, the mean adherence found was greater than $96 \%{ }^{(18)}$.

In the present study, the group with the lowest adherence was one of the individuals with metastatic disease. Through identifying this group, investment in a more effective multiprofessional follow-up during the routine consultations would become possible, thereby ensuring early detection of potential non-adherent individuals and enabling discussion of reinforcement measures or a change to intravenous drugs ${ }^{(25)}$.

Although adherence to oral anti-cancer therapy generally seems to be greater than in cases of other diseases, most studies have shown that a number of cancer patients may always need specific interventions to ensure adherence. Patient education provided by pharmacists can improve the results regarding adherence to oral medications ${ }^{(3,30)}$. These professionals could be part of the healthcare team in determining strategies to evaluate and improve adherence to oral treatment.

A study by Wu et al. among chronically diseased individuals, in which pharmacists carried out counseling over the telephone with patients who were taking several medications orally, demonstrated that this action led to greater adherence to treatment over a 2 -year period ${ }^{(20,32)}$.

In the present study, there were no strong correlations between adherence and the grades attributed in the functional scales and the symptoms highlighted through the EORTC QLQ-C30 quality-of-life questionnaire, either at the beginning of the study (before chemotherapy) or at the end of the evaluations, after 3-4 cycles of chemotherapy.

Investigations and actions to promote adherence focus on patients or their caregivers. The factors that interfere with adherence to therapy centered on patients or caregivers, thus reflecting the individual, family and social context. Motives that sometimes are not important by healthcare professionals are often the ones that really determine whether a patient follows a given treatment ${ }^{(32)}$.

We found an improvement on the functional scale for physical capacity, before and after chemotherapy, among patients who made use of capecitabine in association with other intravenous chemotherapeutic drugs, and among rectal cancer patients, which reflects a clinical improvement in the disease, due to the treatment. There was also an improvement in the emotional capacity and in fatigue among the 
rectal cancer patients. Patients treated with capecitabine and intravenous chemotherapy, had less dyspnea, compared to the others patients studied. The patients had no clinical cause, as pleural effusion or pulmonary metastases to justify dyspnea. We believe that they interpreted fatigue or anxiety as dyspnea. Patients undergoing treatment with capecitabine plus intravenous chemotherapy had a worsening of financial difficulties.

We did not find any statistically significant correlation between adherence and the functional and symptom scales of the EORTC quality-of-life questionnaire, before and after chemotherapy, with the exception of dyspnea. Patients with a lower degree of dyspnea had greater adherence. There was a belief among the patients regarding side effects and the efficacy of the treatment. The lack of correlation found between quality of life and adherence may have been due to fear of reporting side effects among the patients. The patients believed that if they reported significant side effects to their oncologist, their dose might be reduced and the treatment might even be suspended ${ }^{(10)}$. The patients expected, above all, that their treatment should have maximum efficacy and considered that this result would be associated with maximum use of the prescribed medications.

Improvement of adherence depends greatly on higher ef- ficiency of communication between the healthcare team and the patient, especially when dealing with practical aspects of the morbid condition and its treatment, as well as physiological factors and palpable side effects from using medications. The adherence rates in the present study may have increased partly due to the increased attention given to the patient by the interviewer. The EORTC QLQ-C30 qualityof-life questionnaire considers these issues and, even if no strategy to increase adherence is deliberately used, patients feel more responsible for their own treatment because it is being monitored.

In conclusion, the percentage adherence to oral chemotherapy with capecitabine among the patients was greater than $80 \%$, which is a good percentage. The score from the EORTC QLQ-C30 quality-of-life questionnaire improved after chemotherapy, in relation to the emotional capacity and fatigue scales for rectal cancer cases, and for all the patients in relation to physical capacity. This improvement was possibly secondary to the benefits from the treatment. The only correlation found between adherence and the score from the EORTC QLQ-C30 quality-of-life questionnaire was in relation to dyspnea. Patients' adherence and the dyspnea symptom scale had an inversely proportional correlation.

Figueiredo Jr AG, Forones NM. Estudo de aderência a capecitabina em pacientes com câncer colorretal e câncer de mama metastático. Arq Gastroenterol. 2014,51(3):186-91

RESUMO - Contexto - A capecitabina, uma droga oral, é tão eficaz quanto as drogas quimioterápicas tradicionais. Objetivo - Investigar a adesão ao tratamento oral com capecitabina para câncer de mama e colorretal e determinar qualquer correlação com as mudanças na qualidade de vida do paciente. Métodos - Pacientes com câncer colorretal ou de mama em uso de capecitabina foram incluídos. A cada consulta os pacientes trouxeram a medicação restante. O questionário de qualidade de vida QLQ- C30 foi aplicado na primeira visita e 8-12 semanas após o tratamento. Resultados - Trinta pacientes foram avaliados. A adesão foi de 88,3\% para o câncer de cólon metastático, 90,4\% para o de cólon não-metastático, 94,3\% para o de reto e 96,2\% para o de mama metastático. Com exceção da dispnéia, não houve forte correlação entre adesão e as taxas European Organisation for Research and Treatment of Cancer QLQ-C30 em relação a escala funcional ou de sintomas no início ou após quimioterapia. Conclusão - O nível de adesão foi bom, embora não houvesse adesão absoluta ao tratamento com capecitabina oral. Os profissionais de saúde, portanto, precisam dar maior atenção a pacientes em regimes de tratamento oral. Os pacientes com menor grau de dispneia tiveram maior adesão.

DESCRITORES - Neoplasias colorretais, terapia. Neoplasias da mama, terapia. Adesão à medicação. Questionários. 


\section{REFERENCE}

1. Aisner, J. Overview of the changing paradigm in cancer treatment: oral chemotherapy. Am Journal Health-SysT Pharm. 2007,64:S4-7.

2. Anderson KR, Chambers CR, Lam N, Yau PS, Cusano F, Savoie ML, Sheikh N. Medication adherence among adults prescribed imatinib, dasatinib, or nilotinib for the treatment of chronic myeloid leukemia. J Oncol Pharm Pract. 2014 Feb 6. [Epub ahead of print]

3. Beney J, Bero LA, Bond C.Expanding the roles of outpatient pharmacists: effects on health services utilization, costs, and patient outcomes. Cochrane Database Syst Rev. 2000;CD000336. Review.

4. Bhattacharya D, Easthall C, Willoughby KA, Small M, Watson S. Capecitabine non-adherence: Exploration of magnitude, nature and contributing factors. J Oncol Pharm Pract. 2012;18:333-42.

5. Bourmaud A, Pacaut C, Melis A, Tinquaut F, Magné N, Merrouche Y, Chauvin F. Is oral chemotherapy prescription safe for patients? A cross-sectional survey. Ann Oncol. 2014;25:500-4.

6. Cantrell CR, Eaddy MT, Shah MB, Regan TS, Sokol MC. Methods for evaluating patient adherence to antidepressant therapy: a real-world comparison of adherence and economic outcomes. Med Care. 2006;44:300-3.

7. Cramer JA, Roy A, Burrell A et al. Medication compliance and persistence: terminology and definitions. Value Health 2008;11:44-7.

8. Cutsem EV, Findlay M, Osterwalder B. Capecitabine, an oral fluoropyrimidine carbamate with substantial activity in advanced colorectal cancer: results of a randomized phase II study. J Clin Oncol. 2000;18:1337-45.

9. Franceschini J, Jardim JR, Fernandes ALG, Jamnik S, Santoro IL. Reprodutibilidade da versão em português do Brasil do European Organization for Research and Treatment of Cancer Core Quality of Life Questionnaire em conjunto com seu módulo específico para câncer de pulmão. J Bras Pneumol. 2010;36:595-602

10. .Fellowes D, Fallowfield LJ, Saunders CM, Houghton J. Tolerability of hormone therapies for breast cancer: how informative are documented symptom profiles in medical notes for 'welltolerated' treatments? Breast Can Res Treat. 2001;66:73-81.

11. Garcia RA. Cumplimiento terapêutico: qué conocemos de España. Aten Primaria. 2001;27:559-68.

12. Goodin S. Oral chemotherapeutic agents: understanding mechanisms of action and drug interactions. Am J Health-Syst Pharm. 2007;64:S15-24.

13. Hoff PM, Cassid J, Schmoll HJ. The Evolution of Fluoropyrimidine Therapy: From Intravenous to Oral. Oncologist. 2001;6:3-11.

14. Instituto Nacional de Câncer. Estimativas/2012. Brasil. Ministério da Saúde Incidência de câncer no Brasil. 2012. Rio de Janeiro. [cited 2014 Feb 09]. Available from: http://www.inca.gov.br/estimativa

15. Kripalani S, Yao X, Haynes RB. Interventions to enhance medication adherence in chronic medical conditions: a systematic review. Arch Intern Med. 2007; $167: 540-50$
16. Lash TL, Fox MP, Westrup JL, Fink AK, Silliman RA. Adherence to tamoxifen over the five-year course. Breast Cancer Res Treat. 2006;99:215-20.

17. Liu G, Franssen E, Fitch MI, Warner E. Patient preferences for oral versus intravenous palliative chemotherapy. J Clin Oncol. 1997;15:110-5.

18. Mayer RJ. Should capecitabine replace infusional fluorouracil and leucovorin when combined with oxaliplatin in metastatic colorectal cancer? J Clin Oncol. 2007;20:25:4165-7.

19. Muss HB, Berry DA, Cirrincione CT, Theodoulou M, Mauer AM, Kornblith AB, et al. Adjuvant chemotherapy in older women with early-stage breast cancer. N Engl J Med. 2009;360:2055-65.

20. O'Connor, PJ. Improving Medication Adherence: Challenges for Physicians, payers, and policy makers Arch Intern Med. 2006;166:17-25.

21. Osborne CK. Tamoxifen in the treatment of breast cancer. N Engl J Med. 1998;339:1609-18.

22. Osterberg L, Blaschke T. Adherence to medication. N Engl J Med. 2005;353:48797.

23. Partridge AH. Avom J, Wang PS, Winner EP. Adherence to therapy with oral antineoplastic agent. J Natl Cancer Inst. 2002;94:652-61.

24. Pullar T, Kumar S, Tindall H, Feely M. Time to stop counting the tablets? Clin Pharmacol Ther. 1989;46:163-8.

25. Rosen MI, Rigsby MO, Salahi JT, Ryan CE, Cramer JA. Electronic monitoring and counseling to improve medication adherence. Behav Res Ther. 2004;42:409-22.

26. Ruddy K, Mayer E, Partridge A. Patient adherence and persistence with oral anticancer treatment. CA Cancer J Clin. 2009; 59:56-66.

27. Smith IE, Dowsett M. Aromatase inhibitors in breast cancer. N Engl J Med.2003;348:2431-42.

28. Soran A, Nesbitt L, Mamounas EP, Lembersky B, Bryant J, Anderson S, Brown A, Passarello M. Centralized medical monitoring in phase III clinical trials: the National Surgical Adjuvant Breast and Bowel Project (NSABP) experience. Clin Trials. 2006;3:478-85

29. Waterhouse DM, Calzone KA, Mele C, Brenner DE. Adherence to oral tamoxifen a comparison of patient self-report, pill counts, and microelectronic monitoring. J Clin Oncol. 1993;11:1189-97.

30. Walko CM, Lindley C. Capecitabine: a review. Clin Ther.2005;27:23-44.

31. World Health Organization. World Cancer Report, 2008. International Agency for Research on Cancer, Lyon. 2009. [cited 2014 Feb 16]. Available from: http:// www.iarc.fr/en/publications/pdfs-online/wcr/2008/wer_2008.pdf

32. Wu, JY, Leung WY, Chang S, Lee B, Zee B, Tong PC, Chan JC. Effectiveness of telephone counselling by a pharmacist in reducing mortality in patients receiving polypharmacy: randomised controlled trial. BMJ. 2006.333:522,

Received 21/2/2014

Accepted 14/4/2014. 